CLINICAL STUDY

\title{
Acute exercise increases adipose tissue interstitial adiponectin concentration in healthy overweight and lean subjects
}

\author{
Lise Højbjerre, Mary Rosenzweig, Flemming Dela, Jens M Bruun ${ }^{1}$ and Bente Stallknecht \\ Department of Biomedical Sciences, The Panum Institute, The Copenhagen Muscle Research Centre, University of Copenhagen, Blegdamsvej 3, DK-2200 \\ Copenhagen N, Denmark and ${ }^{1}$ Department of Endocrinology and Metabolism C, Aarhus University Hospital, Aarhus Sygehus, DK-8000 Aarhus C, \\ Denmark \\ (Correspondence should be addressed to B Stallknecht; Email: b.stallknecht@mfi.ku.dk)
}

\begin{abstract}
Objective: We studied how an acute bout of exercise influences expression and concentration of adiponectin and regulators of adiponectin in adipose tissue and plasma.

Design and methods: Eight overweight and eight lean males were examined by large-pore microdialysis in s.c. abdominal adipose tissue (SCAAT) and had arterialized blood sampled. On one day subjects rested for $3 \mathrm{~h}$, exercised for $1 \mathrm{~h}$ at $55 \%$ of maximal oxygen uptake and rested again for $2.5 \mathrm{~h}$, and on another day subjects rested for $6.5 \mathrm{~h}$. On the day including exercise SCAAT was biopsied before and after exercise. Results: Exercise increased the SCAAT interstitial adiponectin concentration in both overweight and lean subjects and concentrations did not differ between groups. Plasma adiponectin did not increase during exercise and was similar in overweight and lean subjects. Adiponectin mRNA in SCAAT decreased during exercise and was similar in overweight and lean subjects. Surprisingly, the interstitial adiponectin concentration in SCAAT was only $20 \%$ of the plasma concentration. SCAAT interleukin-6 (IL-6) microdialyzate and plasma concentrations and SCAAT IL-6 mRNA increased during exercise in both groups. Tumor necrosis factor- $\alpha$ (TNF- $\alpha$ ) plasma concentration did not change during exercise in any of the groups, but SCAAT TNF- $\alpha$ mRNA increased after exercise in both groups. Furthermore, exercise decreased SCAAT leptin mRNA with no change in resistin mRNA.

Conclusions: Acute exercise increases adipose tissue interstitial adiponectin concentration in both overweight and lean subjects with no major changes in plasma adiponectin concentration. The interstitial concentration of adiponectin in SCAAT is only $20 \%$ of that in plasma.
\end{abstract}

European Journal of Endocrinology 157 613-623

\section{Introduction}

Adiponectin is a $30-\mathrm{kDa}$ protein that is predominantly expressed in adipocytes $(1,2)$ and circulating adiponectin concentrations are high in both humans and rodents varying from 2 to $30 \mu \mathrm{g} / \mathrm{ml}(3,4)$. Adiponectin forms trimers which circulate in plasma as multimeric structures of up to four-six trimers $(>400 \mathrm{kDa})(4-8)$ and bind to two receptors, AdipoR1 (predominantly skeletal muscle and adipose tissue) and AdipoR2 (predominantly liver) $(9,10)$. The physiological function of adiponectin is largely unknown, but it has been suggested to play a regulatory role in substrate metabolism in skeletal muscle and liver via AMP-activated protein kinase (AMPK) $(4,11-13)$.

Expression and secretion of adiponectin are, in contrast to many other adipokines, reduced in a variety of obese and insulin-resistant states (3, 14-18). Along this line, adiponectin expression increases with weight loss and improved insulin sensitivity $(16,19)$, but it is not yet established whether decreased adiponectin levels are a cause or a consequence of a dysregulated metabolic state (20). The association between adiponectin levels and insulin resistance is confirmed by studies showing that the insulin-sensitizing drug, thiazolidinedione (TZD), significantly increases plasma adiponectin concentrations in insulin-resistant humans and rodents $(21,22)$. Even treatment of insulin-sensitive subjects with TZD has been demonstrated to significantly increase plasma adiponectin concentrations (23).

Both chronic exercise training and acute exercise are also capable of increasing insulin sensitivity, and this might be related to an increase in plasma adiponectin concentration. Recent studies have examined this and provided inconsistent evidence $(15,24-38)$. The majority of studies concluded that chronic, aerobic exercise training has no effect on plasma adiponectin concentration $(24,26,27,30,32-36)$. However, a training study conducted by Kriketos et al. (29) revealed substantially elevated plasma adiponectin concentrations (260\% above baseline values) after only two to three bouts of moderate intensity exercise in overweight males with no change in body weight. Also, Ring-Dimitrou et al. (38) recently found that 12 months of exercise training increased 
plasma adiponectin in middle-aged adults with predisposition to metabolic syndrome. Moreover, Bluher et al. (15) found that 4 weeks of physical training increased plasma adiponectin as well as skeletal muscle AdipoR1 and AdipoR2 in 20 type 2 diabetic, 20 glucose intolerant, and 20 glucose-tolerant subjects.

Three studies $(25,28,31)$ in healthy subjects found no effect of acute exercise on plasma adiponectin concentration, and additionally Punyadeera et al. (31) found skeletal muscle AdipoR1 and AdipoR2 mRNA expression to be unchanged by an acute bout of exercise. In contrast, a study by Jürimäe et al. (37) demonstrated significant exercise-induced changes in plasma adiponectin concentration. Highly trained male rowers completed an all-out $6000 \mathrm{~m}$ rowing test ( $\sim 20 \mathrm{~min})$. After $30 \mathrm{~min}$ of recovery, the adiponectin concentration was increased by $20 \%$ when compared with basal levels. In another study Jürimäe et al. (36) found that the performance level of rowers modified their plasma adiponectin response to an acute $2000 \mathrm{~m}$ bout of rowing. In rowers selected for the national team the rowing bout did not affect plasma adiponectin, but in non-selected rowers the plasma adiponectin concentration decreased.

To obtain a better understanding of the short-term regulation of adiponectin secretion, we measured not only plasma adiponectin but also adiponectin mRNA expression and adiponectin concentration in microdialyzate from s.c. abdominal adipose tissue (SCAAT) of overweight and lean subjects before, during, and after an exercise bout. No studies have previously described the absolute interstitial concentration of adiponectin in adipose tissue, and we therefore also performed a microdialysis perfusion rate calibration study in SCAAT to estimate this concentration. Interleukin-6 (IL-6) and tumor necrosis factor- $\alpha$ (TNF- $\alpha$ ) are potent inhibitors of adiponectin expression and secretion in adipose tissue $(16,17,39)$, and previous studies have demonstrated that exercise increases plasma IL-6 $(40,41)$, while inconsistent findings exist as for the effect of exercise on TNF- $\alpha$ (41). As potential regulators of adiponectin secretion during exercise, we also measured IL- 6 and TNF- $\alpha$ plasma concentrations as well as IL- 6 microdialyzate concentration and IL- 6 and TNF- $\alpha$ expression in SCAAT.

Thus, the purpose of this study was threefold: 1) to address the question of how an acute bout of exercise influences adiponectin concentrations in plasma and adipose tissue in healthy, young, overweight, and lean males, 2) to determine the absolute interstitial concentration of adiponectin in adipose tissue, and 3) to assess exercise-induced changes in potential regulators of adiponectin.

\section{Materials and methods}

\section{Subjects}

Eight overweight (body mass index (BMI): 28.0 \pm 0.3 $($ mean \pm s.e.m. $) \mathrm{kg} / \mathrm{m}^{2}$ ) and eight lean (BMI: $22.8 \pm$
$0.5 \mathrm{~kg} / \mathrm{m}^{2}$ ) male subjects were selected to participate in the study. The ethnic status of the subjects was Caucasian. Inclusion criteria were male, aged 20-30 years; maximal oxygen uptake $\left(\mathrm{VO}_{2 \max }\right) 35-55 \mathrm{ml} / \mathrm{kg}$ body mass per min and BMI $18.5-24.9 \mathrm{~kg} / \mathrm{m}^{2}$ (lean) or $25.0-29.9 \mathrm{~kg} / \mathrm{m}^{2}$ (overweight). Fat percentage determined by dual-energy X-ray absorptiometry (DEXA) scanning was used to validate BMI inclusion criteria. Subjects in the age group 23-25 years with a fat percentage of $12-16 \%$ were categorized as lean and if they had a fat percentage of $16-20 \%$ they were categorized as overweight. Subjects more than 25 years old with a fat percentage of 13-18\% were categorized as lean and those with 18-23\% were categorized as overweight.

Groups were matched with respect to age and cardiorespiratory fitness. Subject characteristics are shown in Table 1. Exclusion criteria included disease, use of medicine, daily smoking, and first degree relatives with type 2 diabetes. The subjects were given an oral and written description of the study and the possible risks and discomfort involved before giving their voluntary oral and written content to participate. All procedures used conformed to the 'Declaration of Helsinki II' and the study was approved by the Ethical Committee of Copenhagen and Frederiksberg, Denmark (project no (KF) 01-126/03).

\section{Pre-testing}

Prior to experiments $\mathrm{VO}_{2 \max }$ was measured using a recumbent cycle ergometer exercise protocol. Subjects exercised (Ergo-line cycle, Ergo-metrics 900L, Bitz, Germany) initially at $75 \mathrm{~W}$ for $5 \mathrm{~min}$, and thereafter the workload was increased by $35 \mathrm{~W}$ every 1 min until exhaustion. Oxygen uptake and carbon dioxide output were measured by means of an Oxycon Pro System (Jaeger, Hoechberg, Germany) using facemask and breath to breath techniques. On the same day, body composition was determined by a DEXA full body scanning (DPX-IQ, software version 4.7e, Lunar Radiation Corporation, Madison, WI, USA). Abdominal

Table 1 Subject characteristics.

\begin{tabular}{lrr}
\hline & Overweight & \multicolumn{1}{c}{ Lean } \\
\hline Age (years) & $26.3 \pm 0.8$ & $26.0 \pm 0.7$ \\
Weight $(\mathrm{kg})^{*}$ & $93.6 \pm 1.4$ & $74.6 \pm 1.7$ \\
Height $(\mathrm{cm})$ & $183.1 \pm 1.5$ & $180.9 \pm 0.8$ \\
Body mass index $\left(\mathrm{kg} / \mathrm{m}^{2}\right)^{*}$ & $28.0 \pm 0.3$ & $22.8 \pm 0.5$ \\
Fat percentage $(\%)^{*}$ & $23.0 \pm 0.5$ & $14.0 \pm 1.0$ \\
${\text { Abdominal skinfold }(\mathrm{mm})^{*}}_{\text {VO }_{2 \max }(\mathrm{ml} / \mathrm{min} \text { per kg lean }}$ & $32.6 \pm 1.5$ & $20.5 \pm 2.2$ \\
body mass) & $54.6 \pm 2.2$ & $57.1 \pm 1.5$ \\
VO $_{2 \max }(\mathrm{ml} / \mathrm{min}$ per kg body mass) & & \\
HOMA-IR & $40.1 \pm 1.5$ & $46.2 \pm 1.4$ \\
& $0.92 \pm 0.1$ & $0.89 \pm 0.2$
\end{tabular}

Data are presented as mean \pm S.E.M. for eight overweight and eight lean subjects. $\mathrm{VO}_{2 \max }$, maximal oxygen uptake. HOMA-IR, homeostasis model assessment insulin resistance. ${ }^{\star} P<0.001$ for overweight when compared with lean subjects. 
skin fold thickness was measured by a caliper (Lafayette Instrument Company, Lafayette, IN, USA).

\section{Experimental design}

Each subject completed two experimental days separated by $\sim 2$ weeks. The days were termed the 'exercise day' and the 'resting day' and were performed in a randomized order. On the exercise day subjects rested for $3 \mathrm{~h}$, exercised for $1 \mathrm{~h}$ at $55 \%$ of $\mathrm{VO}_{2 \max }$ and rested again for $2.5 \mathrm{~h}$, and on the resting day subjects rested for $6.5 \mathrm{~h}$. No adverse effects of exercise were reported.

\section{Protocol}

Subjects arrived at the laboratory at $0800 \mathrm{~h}$ by car or public transportation after a 12-h fast. Food intake might affect the level of hormones and metabolites. To ensure a minimum of variability between subjects we required that participants arrived in a fasted state. To ensure that the participants were arriving in the laboratory in a fasted state, we measured fasting glucose thrice within the first half an hour of arrival. We accepted if subjects had stable venous plasma glucose levels $<6.1 \mathrm{mM}$. The subjects had refrained from vigorous physical activity $24 \mathrm{~h}$ prior to the experiment. Large-pore microdialysis probes (see below) were inserted in the SCAAT and left for $120 \mathrm{~min}$ for the insertion trauma to subside as pilot experiments had revealed that $\sim 2 \mathrm{~h}$ were needed to stabilize the interstitial levels of adiponectin. Dialyzate sampling was delayed by $10 \mathrm{~min}$ relative to the rest of the experimental protocol to compensate for the transit time in the outlet tubing. A teflon catheter (BD venflon Pro, $1.3 \times 32 \mathrm{~mm}$, Becton Dickinson, Helsingborg, Sweden) was inserted retrograde into a dorsal hand vein, and arterialized blood (oxygen saturation $>95 \%$ ) was drawn every $30 \mathrm{~min}$. On the exercise day needle biopsies were obtained from SCAAT before and immediately after exercise and $2.5 \mathrm{~h}$ after the end of exercise.

\section{Large-pore microdialysis}

Linear, large-pore microdialysis probes were manufactured in the laboratory from semipermeable hollow fibers (Plasmaflo OP-05, Asahi Medical Co., Ltd, Tokyo, Japan) with a molecular mass cutoff above $950 \mathrm{kDa}$, and an inner/outer diameter of $0.34 / 0.44 \mathrm{~mm}$. The probe was made by gluing (cyanoacrylate glue) each end of a fiber $1 \mathrm{~cm}$ into hollow nylon tubes with inner/outer diameters of 0.50/0.66 mm (Sterile Tubing, Smith Industries Hythe, Kent, UK). The distance between the two nylon tubes exposed $4 \mathrm{~cm}$ of the fiber. A thin steel wire (Sandvik 12R10, Sandvik A/S, Brøndby, Denmark) was then inserted through the fiber, and the outlet nylon tube was standardized to $10 \mathrm{~cm}$.
Prior to the insertion of microdialysis probes, the skin close to both the insertion and the exit points were anaesthetized with $0.2 \mathrm{ml}$ lidocaine (Lidokain SAD, $5 \mathrm{mg} / \mathrm{ml}$, Sygehus Apotekerne, Denmark). Using an $18 \mathrm{G}$ cannula, four microdialysis probes were inserted into the SCAAT $\sim 4 \mathrm{~cm}$ lateral to the umbilicus on the left side and with $1.5 \mathrm{~cm}$ between probes. The probes were perfused with Ringer acetate containing $2 \mathrm{mM}$ glucose using a high precision syringe pump (CMA100, CMA Microdialysis AB, Solna, Sweden) at a rate of $1 \mu \mathrm{l} / \mathrm{min}$.

Dialyzate was collected in $250 \mu \mathrm{l}$ tubes, and the weight of the sampled fluid was determined in order to validate the perfusion rate. The tubes were placed in microvial racks (CMA Microdialysis $\mathrm{AB}$ ) that were put in a plastic bag with a moist piece of gauze and immediately frozen and stored at $-80{ }^{\circ} \mathrm{C}$ until analyses. Dialyzates that did not contain the expected volume, defined as deviating more than $5 \mu \mathrm{l}$ from the expected volume of $30 \mu \mathrm{l}$, or were light pink due to bleeding around the probe were excluded.

\section{Dialyzate analysis}

Dialyzate concentrations of adiponectin were measured by a human RIA (Linco Diagnostics Inc., St Charles, MO, USA) and dialyzate concentrations of IL- 6 were measured by a high-sensitivity human ELISA (R\&D Systems Inc., Minneapolis, MN, USA). The inter- and intra-assay coefficients of variation for the assays were 9.3 and $1.8 \%$ (adiponectin), and 7.2 and $7.8 \%$ (IL-6) respectively.

\section{Determination of interstitial adiponectin concentrations}

In ten subjects (five overweight and five lean), the variable perfusion rate calibration technique $(42,43)$ was used to estimate the concentration of adiponectin in SCAAT interstitial fluid. On the resting day, three additional large-pore microdialysis probes were placed in SCAAT lateral to the umbilicus on the right side and perfused with Ringer acetate containing $2 \mathrm{mM}$ glucose at $1 \mu \mathrm{l} / \mathrm{min}$. The dialyzate from the first $120 \mathrm{~min}$ was discarded, and subsequently the perfusion rate was consecutively varied $(0.5,10,1,0.25,5 \mu \mathrm{l} / \mathrm{min})$. At each flow rate, dialyzate was sampled after allowance of time for equilibration between the dialyzate and the interstitial fluid. After analysis of samples, dialyzate adiponectin concentrations were plotted as a function of perfusion rate (Fig. 1), and the dialyzate concentration for a perfusion rate of zero was estimated by non-linear least-squares regression. This concentration equals the interstitial concentration. The relative recovery (RR) of adiponectin for a perfusion rate of $1 \mu \mathrm{l} / \mathrm{min}$ was calculated as the dialyzate adiponectin concentration at $1 \mu \mathrm{l} / \mathrm{min}$ divided by the interstitial adiponectin concentration. Mean adiponectin RR was $0.19 \pm 0.04$ and $0.19 \pm 0.03(P=0.94)$ for overweight and lean subjects respectively, and accordingly an RR of 0.19 was 


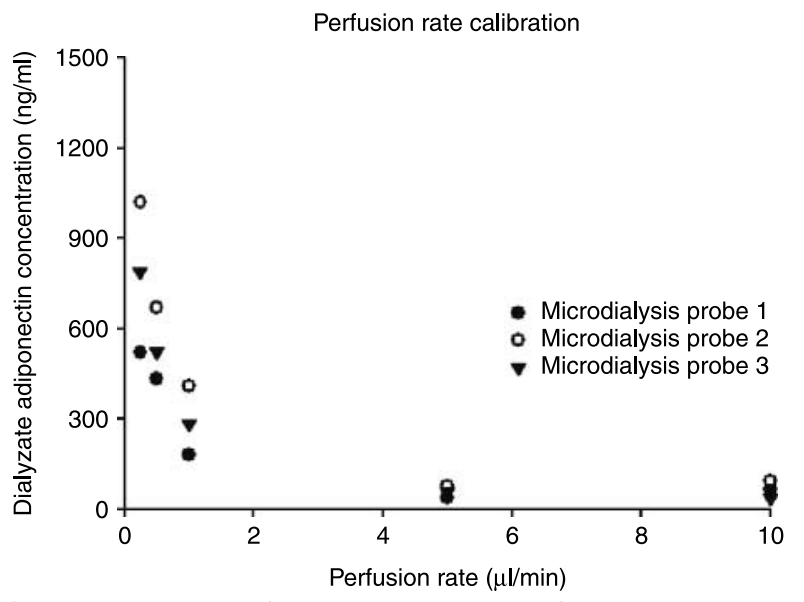

Figure 1 Variable perfusion rate calibration of three microdialysis probes in one subject. Three large-pore microdialysis probes were placed in s.c. abdominal adipose tissue and consecutively perfused at five different perfusion rates: $0.5,10,1,0.25$, and $5 \mu \mathrm{l} / \mathrm{min}$. At each flow rate, dialyzate was sampled and dialyzate adiponectin concentrations were plotted as a function of perfusion rate. The dialyzate concentration for a perfusion rate of zero was estimated by non-linear least-squares regression, and this concentration equals the interstitial concentration.

used to calculate individual interstitial adiponectin concentrations at rest and during exercise.

\section{Blood collection and analysis}

Blood samples were collected and distributed in iced tubes containing EDTA for analysis of free fatty acids (FFA), glycerol, IL- 6 , and TNF- $\alpha$; and trasylol/EDTA for analysis of insulin and adiponectin. The tubes were centrifuged in a Hettich Centrifuge (Hettich Labinstrument ApS, Hvidovre, Denmark) at $4{ }^{\circ} \mathrm{C}$ for $10 \mathrm{~min}$. The plasma for analysis of IL-6, adiponectin, and FFA was stored at $-80{ }^{\circ} \mathrm{C}$ and plasma for analysis of TNF- $\alpha$, glycerol, and insulin was stored at $-20^{\circ} \mathrm{C}$. Hematocrit was determined in duplicate on all blood samples using ARIS Micro Hematocrit tubes (Modulohm AS, Herlev, Denmark). Blood glucose was determined by an ABL 625 (Radiometer, Copenhagen, Denmark). Blood glucose and insulin concentrations determined at time 0 min were used to estimate insulin resistance by the homeostasis model assessment (HOMA-IR) method. HOMA-IR was calculated as fasting insulin $(\mu \mathrm{U} / \mathrm{ml})$ and fasting glucose $(\mathrm{mM}) / 22.5$ (44). Plasma concentrations of adiponectin and IL- 6 were measured by the same kits as used for measuring dialyzate concentrations of adiponectin and IL-6 (see above). Plasma TNF- $\alpha$ and insulin concentrations were measured by a high-sensitivity human ELISA (R\&D Systems Inc.) and a human ELISA (DakoCytomatics, Glostrup, Denmark) respectively. Plasma FFA and glycerol were determined using a non-esterified fatty acids (NEFA) C kit (Wako Chemicals, Neuss, Germany) and a food diagnostic glycerol kit (r-Biopharm AG, Darmstadt, Germany) respectively on a Hitachi 912 automatic analyzer (Boehringer Mannheim, Germany).

\section{Determination of mRNA levels}

On the exercise day, needle biopsies were obtained from SCAAT during local analgesia (Lidokain SAD, $5 \mathrm{mg} / \mathrm{ml}$, Sygehus Apotekerne, Roskilde, Denmark) pre-exercise (60 min), immediately after exercise $(120 \mathrm{~min})$, and post exercise $(270 \mathrm{~min})$. A small incision $(<1 \mathrm{~cm})$ was made, and 100-300 mg of SCAAT was removed by suction under sterile conditions. The tissue was immediately washed in isotonic sodium chloride and frozen in liquid nitrogen, and it was kept at $-80{ }^{\circ} \mathrm{C}$ until mRNA extraction. For the real-time reverse transcriptase PCR (RT-PCR), cDNA was made with random hexamer primers (GeneAmp PCR kit, PerkinElmer-Cetus, Norwalk, CT, USA). PCR-mastermix containing the specific target primers (adiponectin, IL6 , TNF- $\alpha$, leptin, or resistin), Hot Star Taq DNA polymerase and SYBR-Green PRC-buffer were then added. Real-time quantification of target mRNA to $\beta$-actin mRNA was performed using an ICycler PCR machine from Bio-Rad (Bio-Rad Laboratories Inc). Target and $\beta$-actin mRNA were amplified in separate tubes and the increase in fluorescence was measured in real time. Threshold cycles $\left(C_{\mathrm{T}}\right)$ were defined as the fractional cycle number at which the fluorescence reached ten times the S.D. of the baseline. Samples were amplified in duplicate and relative gene expression of $\beta$-actin to target was calculated as $1 /\left(2^{\left(C_{\mathrm{T}} \text { Target } \div \mathrm{C}_{\mathrm{T}} \beta-\text { actin }\right)}\right)$.

\section{Statistical analysis}

The computer program SigmaStat for Windows version 3.01 (Systat software, Richmond, CA, USA) was used for statistical analysis. All data are presented as means \pm s.E.M. If data were not normally distributed, a ln-transformation was performed before data analysis. To determine the effect of exercise on various parameters (adiponectin, IL-6, TNF- $\alpha$, FFA, glycerol, glucose, hematocrit), the delta values on the exercise day and the resting day for those parameters were calculated by subtracting the given parameter on the resting day from the parameter at the same time point on the exercise day. Subsequently, a two-way repeated measures ANOVA (RM ANOVA) was performed with delta values for the parameters as the dependent parameter and group (overweight versus lean) and time as factors to reveal a main effect of group and/or time (baseline, during exercise, and post exercise). If a significant interaction between group and time was present in any two-way RM ANOVA, a Student-Newman-Keuls test was used post hoc to locate the difference at a particular time point. To test whether the above-mentioned parameters varied between overweight and lean subjects on the exercise 
and the resting days a two-way RM ANOVA was performed with the absolute values of the parameter as the dependent variable and group and time as factors. This was done for the exercise day and the resting day separately. If a significant interaction between group and time was present in any two-way RM ANOVA, a Student-Newman-Keuls test was used post hoc to locate the difference at a particular time point. To test the effect of exercise on mRNA levels in SCAAT a two-way RM ANOVA was performed with the mRNA level as the dependent variable and group and time as factors. If an interaction was present between group and time in any two-way RM ANOVA, a Student-Newman-Keuls test was used post hoc to locate the difference at a particular time point. An unpaired $t$-test was used for comparison of body composition, cardiovascular fitness, and HOMA-IR between groups. Threshold for significance was set at $P<0.05$.

\section{Results}

\section{Body composition, cardiovascular fitness, and HOMA-IR}

Subject characteristics are summarized in Table 1. Overweight subjects had higher $(P<0.001)$ body weight, BMI, body fat percentage, and abdominal skin fold thickness when compared with lean subjects. Cardiovascular fitness was similar $(P=0.36)$ in the two groups when expressed relative to lean body mass. Also HOMA-IR did not differ $(P=0.93)$ between groups.

\section{Adiponectin}

The interstitial adiponectin concentrations in SCAAT were $936 \pm 245$ and $1160 \pm 219 \mathrm{ng} / \mathrm{ml}(P=0.51)$ in overweight $(n=5)$ and lean $(n=5)$ subjects respectively, as estimated by the variable perfusion rate calibration technique. The corresponding plasma adiponectin concentrations were $5851 \pm 309$ and $5677 \pm$ $767 \mathrm{ng} / \mathrm{ml}(P=0.84)$. Accordingly, the SCAAT interstitial adiponectin concentration was $16 \pm 4$ and $22 \pm$ $5 \%(P=0.39)$ of the plasma adiponectin concentration in overweight and lean subjects.

The delta values of SCAAT interstitial adiponectin concentration were significantly higher $(P<0.001)$ during exercise (time 60-120 min) than at basal (time 0-60 min) and post exercise (time 120-270 min) with no difference $(P=0.84)$ in delta values of SCAAT interstitial adiponectin concentration between overweight and lean subjects (Fig. 2A and B). Accordingly, exercise increased the interstitial adiponectin concentration in adipose tissue to the same extent in overweight and lean subjects. Also in the time period immediately after exercise/rest (time 120-150 min) the delta values of SCAAT interstitial adiponectin concentration were higher $(P=0.046)$ than at basal (time
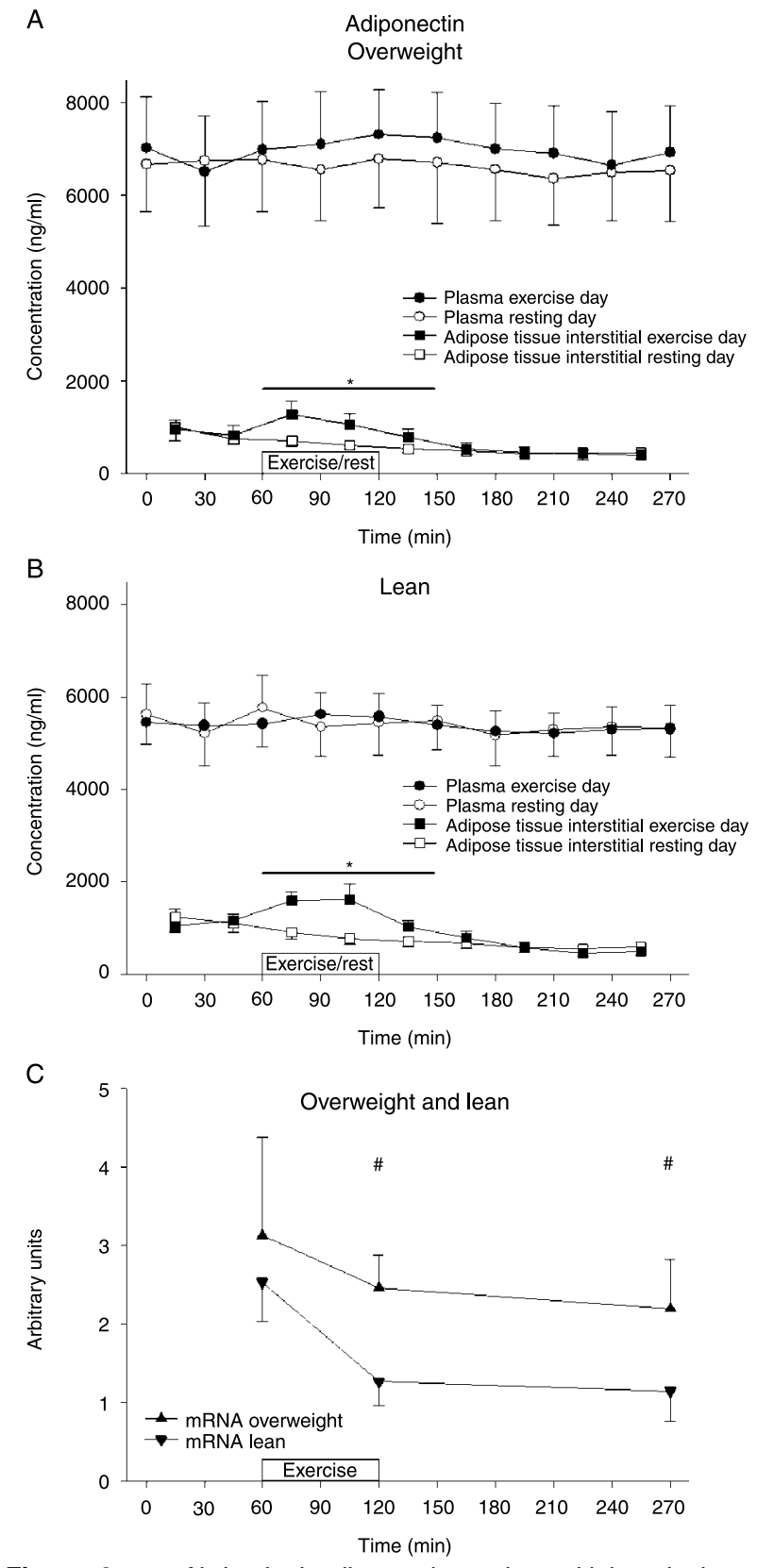

Figure 2 s.c. Abdominal adipose tissue interstitial and plasma concentrations of adiponectin during an exercise (black) and a resting (white) day in eight overweight (A) and eight lean (B) male subjects as well as s.c., abdominal adipose tissue adiponectin relative to $\beta$-actin mRNA (C) during the exercise day in the same subjects. On the exercise day subjects exercised from time 60 to $120 \mathrm{~min}$ at $55 \%$ of maximal oxygen uptake. Data are presented as mean \pm S.E.M. *: Significant increase in delta interstitial adiponectin concentration (exercise minus resting day) when compared with all other time points. "Significant decrease in adiponectin mRNA during and post exercise.

0-30 min) in both overweight and lean subjects. No significant $(P=0.68)$ interaction between groups and time was found. No main effect of group was observed since overweight and lean subjects did not demonstrate 
differences in absolute values of SCAAT interstitial adiponectin concentrations overall on the exercise day $(P=0.18)$ or the resting day $(P=0.23)$. No interaction between group and time was found on the exercise $(P=0.78)$ or the resting $(P=0.95)$ day.

The delta values of plasma adiponectin concentration did not change with time $(P=0.39)$ and were similar $(P=0.42)$ in overweight and lean subjects (Fig. 2A and $B)$ and no interaction between group and time was present $(P=0.79)$. Accordingly, exercise did not change the plasma adiponectin concentration in either overweight or lean subjects. Moreover, no main effect of group was observed since overweight and lean subjects did not demonstrate differences in the absolute plasma adiponectin concentration overall on either the exercise $(P=0.20)$ or the resting day $(P=0.33)$. No interaction between group and time was found on the exercise $(P=0.46)$ or the resting $(P=0.79)$ day.

SCAAT adiponectin mRNA decreased $(P<0.02)$ during and post exercise in both overweight and lean subjects and did not differ $(P=0.11)$ between groups (Fig. 2C). No interaction $(P=0.10)$ between group and time was observed.

\section{Interleukin-6}

The delta values of SCAAT dialyzate IL- 6 concentration were higher after the end of exercise (time 240-270 min) than at basal (time 0-30 min, $P=0.048$ ) and during exercise (time 90-120 min, $P=0.045)$ with no difference $(P=0.82)$ in delta values of SCAAT dialyzate IL- 6 concentration between overweight and lean subjects (Fig. $3 \mathrm{~A}$ and $\mathrm{B}$ ). No interaction was found between group and factor $(P=0.91)$. Accordingly, exercise increased the dialyzate IL- 6 concentration in adipose tissue in the post-exercise period but not during exercise in both overweight and lean subjects. No main effect of group was observed since overweight and lean subjects did not demonstrate differences in absolute SCAAT dialyzate IL-6 concentrations overall on either the exercise $(P=0.22)$ or the resting day $(P=0.41)$. No interaction between group and time was observed on the exercise $(P=0.85)$ or the resting $(P=0.46)$ day.

The delta values of plasma IL- 6 concentration were higher during exercise (time $120 \mathrm{~min}, P=0.02$ ) and post exercise (time $270 \mathrm{~min}, P<0.01$ ) than at basal (time $30 \mathrm{~min})$ and tended to be higher $(P=0.05)$ in overweight than in lean subjects (Fig. $3 \mathrm{~A}$ and $\mathrm{B}$ ). No interaction was observed $(P=0.30)$. Accordingly, exercise increased the plasma IL- 6 concentration and the increase tended to be higher in overweight than in lean subjects. However, no main effect of group was observed since overweight and lean subjects did not demonstrate differences in absolute plasma IL-6 concentration overall on the exercise $(P=0.18)$ or the resting day $(P=0.83)$. No interaction was found on the exercise $(P=0.13)$ or the resting $(P=0.91)$ day.
SCAAT IL-6 mRNA increased $(P<0.001)$ during exercise in both overweight and lean subjects and did not differ $(P=0.19)$ between groups (Fig. 3C). No interaction was observed between group and time $(P=0.41)$.
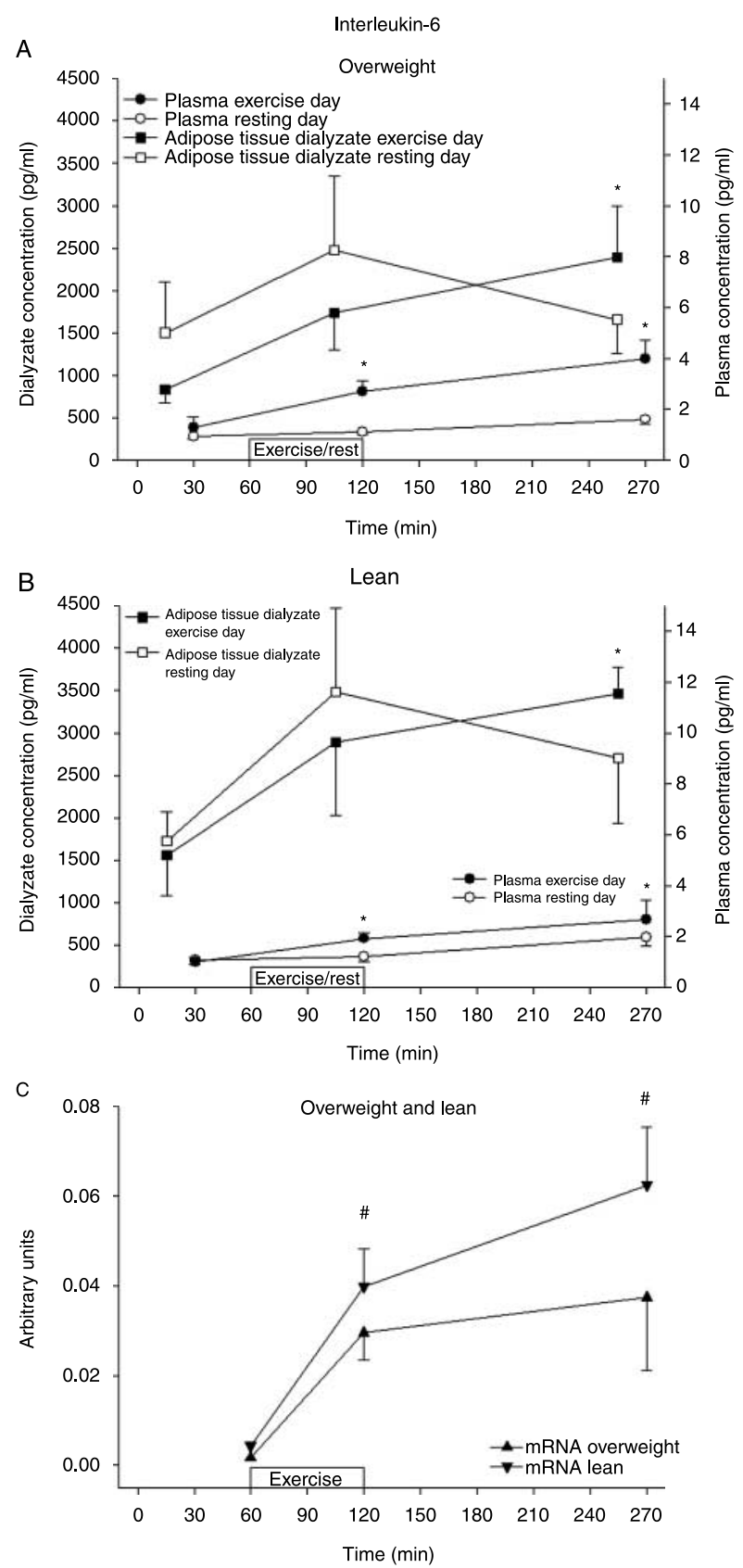

Figure 3 s.c. Abdominal adipose tissue dialyzate and plasma concentrations of interleukin- 6 during an exercise (black) and a resting (white) day in eight overweight $(A)$ and eight lean $(B)$ male subjects as well as s.c., abdominal adipose tissue interleukin- 6 relative to $\beta$-actin mRNA (C) during the exercise day in the same subjects. On the exercise day, subjects exercised from time 60 to $120 \mathrm{~min}$ at $55 \%$ of maximal oxygen uptake. Data are presented as mean \pm S.E.M. ${ }^{*}$ Significant increase in delta interleukin- 6 concentration (exercise minus resting day) when compared with all other time points.

\#Significant increase in interleukin-6 mRNA during and post exercise. 


\section{Tumor necrosis factor- $\alpha$}

The delta values of plasma TNF- $\alpha$ concentration did not change with time $(P=0.27)$ and were similar $(P=0.88)$ in overweight and lean subjects (data not shown). Accordingly, exercise did not change the plasma TNF- $\alpha$ concentration in either overweight or lean subjects. Moreover, no main effect of group was observed since overweight and lean subjects did not demonstrate differences in absolute plasma TNF- $\alpha$ concentration overall on either the exercise $(P=0.16)$ or the resting day $(P=0.21)$. No interaction between group and time was observed on the exercise $(P=0.73)$ or the resting $(P=0.17)$ day.

SCAAT TNF- $\alpha$ mRNA increased $(P<0.01)$ in the post-exercise period in both overweight and lean subjects and did not differ $(P=0.62)$ between groups (Fig. 4A). No interaction between group and time was observed $(P=0.31)$.

\section{Plasma glycerol and FFA}

The delta values of plasma glycerol concentration were higher $(P<0.001)$ during exercise (time 90 and $120 \mathrm{~min}$ ) than at basal (time 0-60 min) and post exercise (time 150-270 min) and delta values of plasma glycerol concentration were similar $(P=0.56)$ in overweight and lean subjects (data not shown). No interaction was observed $(P=0.06)$. Accordingly, exercise increased the plasma glycerol concentration to the same extent in overweight and lean subjects. Moreover, no main effect of group was observed since overweight and lean subjects did not demonstrate differences in absolute plasma glycerol concentration overall on either the exercise $(P=0.25)$ or the resting day $(P=0.63)$. No interaction was found on the exercise $(P=0.19)$ or the resting $(P=0.72)$ day.

Likewise, the delta values of plasma FFA concentration were higher $(P<0.01)$ during exercise (time $120 \mathrm{~min}$ ) than at basal (time $0-60 \mathrm{~min}$ ) and post exercise (time 150-180 min) and were similar $(P=0.85)$ in overweight and lean subjects (data not shown). Also post-exercise (time $270 \mathrm{~min}, P=0.02$ ) concentrations were higher than basal (time $60 \mathrm{~min}$ ) concentration. No interaction was observed between group and time $(P=0.86)$. Accordingly, exercise increased the plasma FFA concentration during exercise and post exercise to the same extent in overweight and lean subjects. Moreover, no main effect of group was observed since overweight and lean subjects did not demonstrate differences in absolute plasma FFA concentration overall on either the exercise $(P=0.55)$ or the resting day $(P=0.56)$. No interaction was observed on the exercise $(P=0.23)$ or the resting $(P=0.66)$ day.

\section{Blood glucose and plasma insulin}

The delta values of blood glucose concentration did not change with time $(P=0.16)$ and were similar $(P=0.49)$

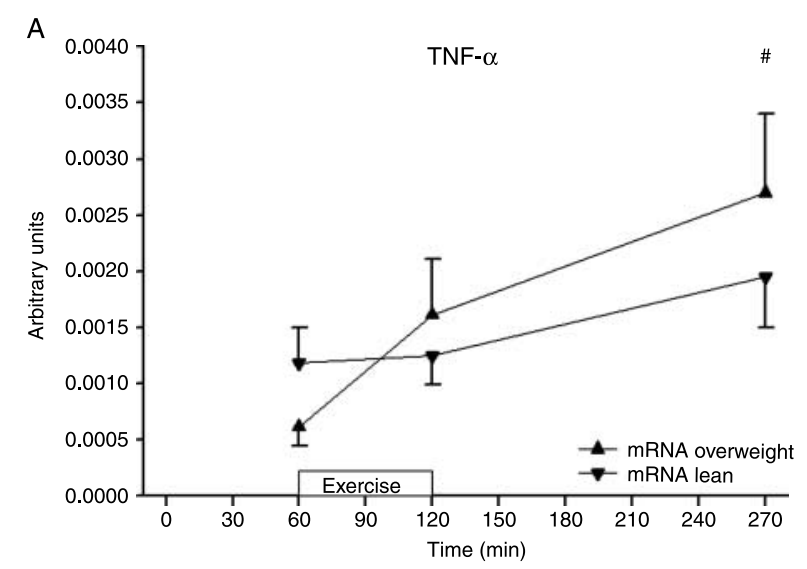

B
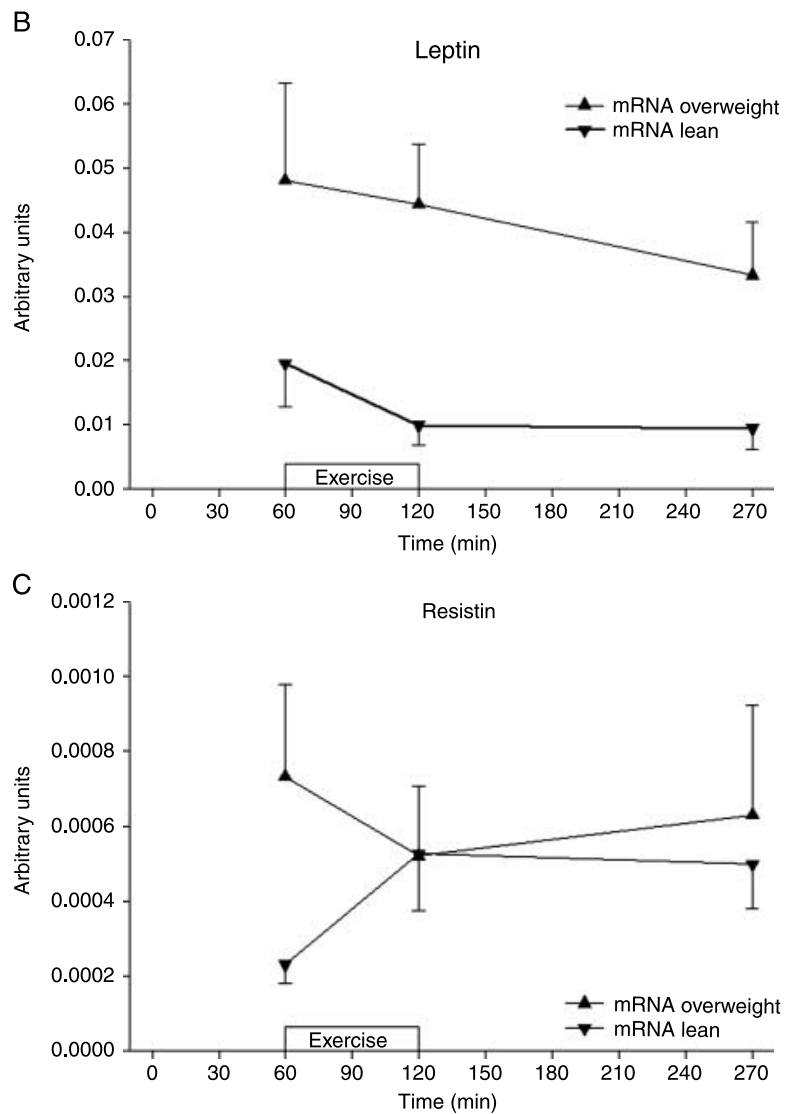

Figure 4 s.c. Abdominal adipose tissue tumor necrosis factor- $\alpha(A)$, leptin (B), and resistin $(C)$ relative to $\beta$-actin mRNA in eight overweight and eight lean male subjects during a day where subjects exercised from time 60 to $120 \mathrm{~min}$ at $55 \%$ of maximal oxygen uptake. Data are presented as mean \pm s.E.M. " Significant increase in tumor necrosis factor- $\alpha$ mRNA post exercise.

in overweight and lean subjects (data not shown). No interaction was observed $(P=0.76)$. Moreover, no main effect of group was observed since overweight and lean subjects did not demonstrate differences in absolute blood glucose concentration overall on either the exercise $(P=0.67)$ or the resting day $(P=0.23)$. 
No interaction was observed on the exercise $(P=0.63)$ or the resting $(P=0.99)$ day.

Also the delta values of plasma insulin concentration did not change with time $(P=0.25)$ and were similar $(P=0.68)$ in overweight and lean subjects (data not shown). No interaction was observed $(P=0.65)$. Moreover, no main effect of group was observed since overweight and lean subjects did not demonstrate differences in absolute plasma insulin concentration overall on either the exercise $(P=0.60)$ or the resting day $(P=0.54)$. No interaction was observed on the exercise $(P=0.89)$ or the resting $(P=0.68)$ day.

\section{Hematocrit}

The delta values of hematocrit tended to change with time $(P=0.08)$ but were similar $(P=0.93)$ in overweight and lean subjects (data not shown). No interaction was observed $(P=0.38)$. Moreover, no main effect of group was observed since overweight and lean subjects did not demonstrate differences in absolute hematocrit overall on either the exercise $(P=0.69)$ or the resting day $(P=0.40)$. No interaction was found on the exercise $(P=0.23)$ or the resting $(P=0.65)$ day.

\section{Adipose tissue leptin and resistin mRNA}

SCAAT leptin mRNA decreased during the exercise $(P=0.04)$ and the post-exercise period $(P<0.01)$ when compared with the basal period, and leptin mRNA was higher $(P=0.004)$ in overweight when compared with lean subjects (Fig. 4B). No interaction between group and time was observed $(P=0.11)$.

SCAAT resistin mRNA was not changed $(P=0.81)$ by exercise and was similar $(P=0.44)$ in overweight and lean subjects (Fig. 4C). No interaction between group and time was observed $(P=0.06)$.

\section{Discussion}

A key finding of the present study is that $1 \mathrm{~h}$ of acute exercise at $55 \%$ of $\mathrm{VO}_{2 \max }$ induces a significant increase in interstitial adiponectin concentration in SCAAT, and thus supports that exercise regulates adiponectin secretion on a short-term basis. Despite altered interstitial adiponectin concentrations we did not find that acute exercise-induced major changes in plasma adiponectin concentration. It has previously been demonstrated that adiponectin is very abundant in plasma and that plasma adiponectin levels are relatively constant during $24 \mathrm{~h}$ (45). Acute physiological changes in plasma adiponectin concentrations are rarely seen which might reflect that a large change in adiponectin secretion rate is required to change the plasma adiponectin concentration because of the relatively large pool of adiponectin in plasma. As the exerciseinduced increase in adipose tissue interstitial adiponectin concentration does not produce a marked increase in plasma adiponectin concentration, we speculate that adiponectin has autocrine/paracrine effects in adipose tissue during exercise, which seems likely as adipocytes and stroma-vascular cells in adipose tissue recently has been found to express receptors for adiponectin (10). Autocrine/paracrine effects could include stimulation of glucose uptake in adipocytes (46) as well as dampening of low-grade inflammation in adipose tissue (47).

Blood flow increases in SCAAT during exercise (48). The increased blood flow contributes to an increased transport of molecules between the adipose tissue interstitial fluid and plasma during exercise. The increased blood flow could also increase the transport of molecules across the microdialysis membrane, and hence increase the RR of molecules from the interstitial space during exercise. Accordingly, the increase in microdialyzate adiponectin during exercise could be due to an increase in recovery of adiponectin with no increase in interstitial adiponectin concentration. We did not measure RR of adiponectin during exercise, but the microdialyzate urea concentration can be used as an indicator of RR $(49,50)$ as interstitial and plasma urea concentrations are constant during the day. We measured microdialyzate and plasma urea concentrations in four subjects and found the concentrations to be unchanged during the exercise day (microdialyzate urea: basal: $3.2 \pm 0.5 \mathrm{mM}$, exercise $3.2 \pm 0.4 \mathrm{mM}$, post exercise $3.1 \pm 0.3 \mathrm{mM}, n=4$; plasma urea: basal: $4.3 \pm 0.4 \mathrm{mM}$, exercise $4.3 \pm 0.4 \mathrm{mM}$, post exercise $4.2 \pm 0.4 \mathrm{mM}, n=4)$. It is therefore not likely that changes in RR during exercise can explain the exerciseinduced increase in microdialyzate adiponectin concentration.

Our study revealed that the effect of acute exercise on interstitial adiponectin concentrations was similar in overweight and lean subjects. Also the absolute interstitial and plasma adiponectin concentrations were similar in overweight and lean subjects. Many studies have demonstrated a strong negative correlation between BMI and plasma adiponectin concentrations (3, 14, 18). Subjects in our overweight group were, however, healthy and only moderately overweight with a mean BMI of 28.0, and this might not induce a decrease in plasma adiponectin concentration. Furthermore, reduced plasma adiponectin concentrations are more closely related to insulin resistance than adiposity $(14,18)$, and the overweight subjects in the present study were according to their HOMA-IR, not insulin resistant.

Surprisingly, we found that SCAAT adiponectin mRNA decreased on the exercise day, but we cannot exclude that this would also have been the case on the resting day. Our theory is that adipocytes contain a preformed pool of adiponectin, as is known for leptin (51), and that exercise can stimulate adipocytes to secrete adiponectin to the interstitial space without any 
increase in adiponectin mRNA thus indicating that exercise induces a post-transcriptional regulation of adiponectin. Two recent studies have demonstrated that stimulators, other than exercise, can induce posttranscriptional regulation of adiponectin. Pereira \& Draznin (52) demonstrated that insulin is able to stimulate secretion of adiponectin from adipocytes and reduce the level of intracellular adiponectin without changes in adiponectin mRNA, and Rasouli et al. (53) showed that pioglitazone increases plasma adiponectin concentrations without an increase in adipose tissue adiponectin mRNA. Furthermore, the exercise-induced increase in interstitial adiponectin concentration in SCAAT could be explained by an increased delivery of adiponectin from plasma to SCAAT caused by an exercise-induced increase in adipose tissue blood flow.

Adiponectin is mainly expressed in adipose tissue $(1,2)$, so a surprising finding of the present study is that the interstitial adiponectin concentration in SCAAT is only $\sim 20 \%$ of the concentration in plasma in resting overweight and lean male subjects. The interstitial adiponectin concentration was determined by the well-established variable perfusion rate calibration technique, which is based upon the principle that the closer to zero the perfusion rate through the microdialysis probe the more complete the equilibration between the interstitial fluid and the microdialyzate $(42,43)$. Explanations for the unexpected finding could be that A) adiponectin forms complexes in the interstitial fluid that are larger than what can be recovered by the microdialysis probe, B) the microdialysis probe drains the interstitial space for adiponectin, $C$ ) other adipose tissue depots than SCAAT, e.g., visceral adipose tissue, which are main secretors of adiponectin, D) transport of adiponectin from adipocytes to plasma is an active, regulated transport process working against the concentration difference, E) adiponectin is tightly bound to transport proteins in plasma resulting in a low free plasma concentration of adiponectin being in equilibrium with the interstitial adiponectin concentration, F) adiponectin is carried in vesicles in the interstitial space, or G) adiponectin is drained from the interstitial fluid by the lymph.

Adiponectin circulates in plasma as complexes of which some are larger than $400 \mathrm{kDa}$ (4-8). Adiponectin complexes could hence be too large to pass the microdialysis membrane, and the actual interstitial adiponectin concentration could be higher than what is measured by the microdialysis probe. However, according to the manufacturer of the microdialysis probe membrane (Asahi Medical), it has a pore size of up to $0.3 \mu \mathrm{m}$ and a permeability of $95 \%$ for molecules as large as $950 \mathrm{kDa}(\mathrm{IgM})$. We confirmed the pore size and that our large-pore microdialysis probes recover IgM as well as high molecular weight adiponectin (data not shown).

Large molecules like adiponectin diffuse slowly through the interstitial space, and if the molecules have a slow turnover rate one could imagine that the interstitial space could be drained by the microdialysis probe. However, already in the interstitial fluid collected immediately after insertion of the microdialysis probes (time 60-120 min) the concentration of adiponectin was considerably lower $(\sim 1 / 3)$ than in plasma (data not shown). At this time point drainage could not have occurred.

We measured the interstitial adiponectin concentration only in SCAAT. There exists controversy as to in which adipose tissue depot adiponectin is most highly expressed $(54,55)$. If adiponectin is predominantly secreted from visceral adipose tissue this could explain the unexpected concentration difference between s.c. abdominal interstitial fluid and plasma. Other possible explanations for the concentration difference are mentioned above. We find the most likely explanations to be that other adipose tissue depots are main secretors of adiponectin and/or that the transport process of adiponectin from adipocytes to plasma is complex.

Exercise has inflammatory consequences and induces marked elevations in plasma IL-6 and other cytokines $(40,41)$. Corroborating previous studies (56) we found that exercise increased plasma IL- 6 concentration and SCAAT IL-6 expression. In the present study, we extended these findings and showed that exercise also increased the concentration of IL- 6 in dialyzate from SCAAT and confirmed (57) that the concentration of IL-6 is markedly higher in dialyzate from SCAAT than in plasma. In the present study exercise did not change the plasma concentration of TNF- $\alpha$, but SCAAT TNF- $\alpha$ expression was increased by exercise. Furthermore, we found exercise to decrease SCAAT leptin expression with no change in SCAAT resistin expression.

IL-6 and TNF- $\alpha$ are known to down-regulate adiponectin expression and secretion from adipocytes $(16,17$, 39), and the mechanism behind the down-regulation of SCAAT adiponectin expression during exercise could be the exercise-induced up-regulation of IL- 6 expression and concentration in SCAAT and/or the exercise-induced increase in TNF- $\alpha$ expression in SCAAT.

The concentration of FFA has been suggested as an acute, positive regulator of adiponectin secretion (58, 59). Exercise increases adipose tissue lipolysis (50), and in the present study exercise significantly increased plasma glycerol and FFA concentrations. A mechanism behind the exercise-induced increase in SCAAT interstitial adiponectin concentration could accordingly be an exercise-induced increase in interstitial FFA concentration in SCAAT.

In conclusion, exercise induces a striking short-term increase in adipose tissue interstitial adiponectin concentration in both overweight and lean subjects, a decrease in adipose tissue adiponectin mRNA, and no major changes in plasma adiponectin concentration, and we speculate that adiponectin has an autocrine/paracrine function in adipose tissue during exercise. The mechanism behind the increase in interstitial adiponectin concentration might be via an increase in FFA concentration. The interstitial concentration of 
adiponectin in SCAAT is only $20 \%$ of the concentration in plasma which indicates that other adipose tissue depots than SCAAT are main secretors of adiponectin and/or that the transport process of adiponectin from adipocytes to plasma is complex.

\section{Acknowledgements}

We highly appreciate the expert technical assistance of Regitze Kraunsøe, Jeppe Bach, Thomas Beck, Lenette Pedersen, and Pia Hornbek. The study was supported by the Danish Diabetes Association.

\section{References}

1 Maeda K, Okubo K, Shimomura I, Funahashi T, Matsuzawa Y \& Matsubara K. cDNA cloning and expression of a novel adipose specific collagen-like factor, apM1 (adipose most abundant gene transcript 1). Biochemical and Biophysical Research Communications $1996221286-289$.

2 Scherer PE, Williams S, Fogliano M, Baldini G \& Lodish HF. A novel serum protein similar to $\mathrm{C} 1 \mathrm{q}$, produced exclusively in adipocytes. Journal of Biological Chemistry 1995270 26746-26749.

3 Arita Y, Kihara S, Ouchi N, Takahashi M, Maeda K, Miyagawa J, Hotta K, Shimomura I, Nakamura T, Miyaoka K, Kuriyama H, Nishida M, Yamashita S, Okubo K, Matsubara K, Muraguchi M, Ohmoto Y, Funahashi T \& Matsuzawa Y. Paradoxical decrease of an adipose-specific protein, adiponectin, in obesity. Biochemical and Biophysical Research Communications 1999257 79-83.

4 Chandran M, Phillips SA, Ciaraldi T \& Henry RR. Adiponectin: more than just another fat cell hormone? Diabetes Care 200326 2442-2450.

5 Pajvani UB, Hawkins M, Combs TP, Rajala MW, Doebber T, Berger JP, Wagner JA, Wu M, Knopps A, Xiang AH, Utzschneider KM, Kahn SE, Olefsky JM, Buchanan TA \& Scherer PE. Complex distribution, not absolute amount of adiponectin, correlates with thiazolidinedione-mediated improvement in insulin sensitivity. Journal of Biological Chemistry 2004 279 12152-12162.

6 Pajvani UB, Du X, Combs TP, Berg AH, Rajala MW, Schulthess T, Engel J, Brownlee M \& Scherer PE. Structure-function studies of the adipocyte-secreted hormone Acrp30/adiponectin. Implications fpr metabolic regulation and bioactivity. Journal of Biological Chemistry $2003 \mathbf{2 7 8} 9073-9085$.

7 Ebinuma H, Miyazaki O, Yago H, Hara K, Yamauchi T \& Kadowaki T. A novel ELISA system for selective measurement of human adiponectin multimers by using proteases. Clinica Chimica Acta 2006372 47-53.

$8 \mathrm{Xu}$ A, Chan KW, Hoo RL, Wang Y, Tan KC, Zhang J, Chen B, Lam MC, Tse C, Cooper GJ \& Lam KS. Testosterone selectively reduces the high molecular weight form of adiponectin by inhibiting its secretion from adipocytes. Journal of Biological Chemistry $200528018073-18080$.

9 Yamauchi T, Kamon J, Ito Y, Tsuchida A, Yokomizo T, Kita S, Sugiyama T, Miyagishi M, Hara K, Tsunoda M, Murakami K, Ohteki T, Uchida S, Takekawa S, Waki H, Tsuno NH, Shibata Y, Terauchi Y, Froguel P, Tobe K, Koyasu S, Taira K, Kitamura T, Shimizu T, Nagai R \& Kadowaki T. Cloning of adiponectin receptors that mediate antidiabetic metabolic effects. Nature $2003 \mathbf{4 2 3} 762-769$.

10 Rasmussen MS, Lihn AS, Pedersen SB, Bruun JM, Rasmussen M \& Richelsen B. Adiponectin receptors in human adipose tissue: effects of obesity, weight loss, and fat depots. Obesity $20061428-35$.

11 Fruebis J, Tsao TS, Javorschi S, Ebbets-Reed D, Erickson MR, Yen FT, Bihain BE \& Lodish HF. Proteolytic cleavage product of
30-kDa adipocyte complement-related protein increases fatty acid oxidation in muscle and causes weight loss in mice. PNAS 2001 98 2005-2010.

12 Mora S \& Pessin JE. An adipocentric view of signaling and intracellular trafficking. Diabetes/Metabolism Research and Reviews $200218345-356$.

13 Yamauchi T, Kamon J, Minokoshi Y, Ito Y, Waki H, Uchida S, Yamashita S, Noda M, Kita S, Ueki K, Eto K, Akanuma Y, Froguel P, Foufelle F, Ferre P, Carling D, Kimura S, Nagai R, Kahn BB \& Kadowaki T. Adiponectin stimulates glucose utilization and fattyacid oxidation by activating AMP-activated protein kinase. Nature Medicine 20028 1288-1295.

14 Weyer C, Funahashi T, Tanaka S, Hotta K, Matsuzawa Y, Pratley RE \& Tataranni PA. Hypoadiponectinemia in obesity and type 2 diabetes: close association with insulin resistance and hyperinsulinemia. Journal of Clinical Endocrinology and Metabolism 200186 1930-1935.

15 Bluher M, Bullen JW, Jr, Lee JH, Kralisch S, Fasshauer M, Kloting N, Niebauer J, Schon MR, Williams CJ \& Mantzoros CS. Circulating adiponectin and expression of adiponectin receptors in human skeletal muscle: associations with metabolic parameters and insulin resistance and regulation by physical training. Journal of Clinical Endocrinology and Metabolism 200691 2310-2316.

16 Bruun JM, Lihn AS, Verdich C, Pedersen SB, Toubro S, Astrup A \& Richelsen B. Regulation of adiponectin by adipose tissue-derived cytokines: in vivo and in vitro investigations in humans. American Journal of Physiology. Endocrinology and Metabolism 2003285 E527-E533.

17 Fasshauer M \& Paschke R. Regulation of adipocytokines and insulin resistance. Diabetologia 200346 1594-1603.

18 Kern PA, Di Gregorio GB, Lu T, Rassouli N \& Ranganathan G. Adiponectin expression from human adipose tissue: relation to obesity, insulin resistance, and tumor necrosis factor-alpha expression. Diabetes 200352 1779-1785.

19 Yang WS, Lee WJ, Funahashi T, Tanaka S, Matsuzawa Y, Chao CL, Chen CL, Tai TY \& Chuang LM. Weight reduction increases plasma levels of an adipose-derived anti- inflammatory protein, adiponectin. Journal of Clinical Endocrinology and Metabolism $2001 \mathbf{8 6}$ 3815-3819.

20 Berg AH, Combs TP \& Scherer PE. ACRP30/adiponectin: an adipokine regulating glucose and lipid metabolism. Trends in Endocrinology and Metabolism 200213 84-89.

21 Berg AH, Combs TP, Du X, Brownlee M \& Scherer PE. The adipocyte-secreted protein Acrp30 enhances hepatic insulin action. Nature Medicine 20017 947-953.

22 Maeda N, Takahashi M, Funahashi T, Kihara S, Nishizawa H, Kishida K, Nagaretani H, Matsuda M, Komuro R, Ouchi N, Kuriyama H, Hotta K, Nakamura T, Shimomura I \& Matsuzawa Y. PPARgamma ligands increase expression and plasma concentrations of adiponectin, an adipose-derived protein. Diabetes 2001 50 2094-2099.

23 Combs TP, Wagner JA, Berger J, Doebber T, Wang WJ, Zhang BB, Tanen M, Berg AH, O'Rahilly S, Savage DB, Chatterjee K, Weiss S, Larson PJ, Gottesdiener KM, Gertz BJ, Charron MJ, Scherer PE \& Moller DE. Induction of adipocyte complement-related protein of 30 kilodaltons by PPARgamma agonists: a potential mechanism of insulin sensitization. Endocrinology 2002143 998-1007.

24 Boudou P, Sobngwi E, Mauvais-Jarvis F, Vexiau P \& Gautier JF. Absence of exercise-induced variations in adiponectin levels despite decreased abdominal adiposity and improved insulin sensitivity in type 2 diabetic men. European Journal of Endocrinology $2003149421-424$.

25 Ferguson MA, White LJ, McCoy S, Kim HW, Petty T \& Wilsey J. Plasma adiponectin response to acute exercise in healthy subjects. European Journal of Applied Physiology and Occupational Physiology $200491324-329$.

26 Hara T, Fujiwara H, Nakao H, Mimura T, Yoshikawa T \& Fujimoto S. Body composition is related to increase in plasma adiponectin levels rather than training in young obese men. European Journal of Applied Physiology and Occupational Physiology 200594 520-526. 
27 Hulver MW, Zheng D, Tanner CJ, Houmard JA, Kraus WE, Slentz CA, Sinha MK, Pories WJ, MacDonald KG \& Dohm GL. Adiponectin is not altered with exercise training despite enhanced insulin action. American Journal of Physiology. Endocrinology and Metabolism 2002283 E861-E865.

28 Kraemer RR, Aboudehen KS, Carruth AK, Durand RT, Acevedo EO, Hebert EP, Johnson LG \& Daniel CV. Adiponectin responses to continuous and progressively intense intermittent exercise. Medicine and Science in Sports and Exercise $2003 \mathbf{3 5}$ 1320-1325.

29 Kriketos AD, Gan SK, Poynten AM, Furler SM, Chisholm DJ \& Campbell LV. Exercise increases adiponectin levels and insulin sensitivity in humans. Diabetes Care 200427 629-630.

30 Marcell TJ, McAuley KA, Traustadottir T \& Reaven PD. Exercise training is not associated with improved levels of C-reactive protein or adiponectin. Metabolism: Clinical and Experimental 2005 54 533-541.

31 Punyadeera C, Zorenc AH, Koopman R, McAinch AJ, Smit E, Manders R, Keizer HA, Cameron-Smith D \& van Loon LJ. The effects of exercise and adipose tissue lipolysis on plasma adiponectin concentration and adiponectin receptor expression in human skeletal muscle. European Journal of Endocrinology 2005 152 427-436.

32 Nassis GP, Papantakou K, Skenderi K, Triandafillopoulou M, Kavouras SA, Yannakoulia M, Chrousos GP \& Sidossis LS. Aerobic exercise training improves insulin sensitivity without changes in body weight, body fat, adiponectin, and inflammatory markers in overweight and obese girls. Metabolism: Clinical and Experimental $2005 \mathbf{5 4} 1472-1479$.

33 Ryan AS, Nicklas BJ, Berman DM \& Elahi D. Adiponectin levels do not change with moderate dietary induced weight loss and exercise in obese postmenopausal women. International Journal of Obesity and Related Metabolic Disorders 200327 1066-1071.

34 Yatagai T, Nishida Y, Nagasaka S, Nakamura T, Tokuyama K, Shindo M, Tanaka H \& Ishibashi S. Relationship between exercise training-induced increase in insulin sensitivity and adiponectinemia in healthy men. Endocrine Journal 200350 233-238.

35 Yokoyama H, Emoto M, Araki T, Fujiwara S, Motoyama K, Morioka T, Koyama H, Shoji T, Okuno Y \& Nishizawa Y. Effect of aerobic exercise on plasma adiponectin levels and insulin resistance in type 2 diabetes. Diabetes Care 200427 1756-1758.

36 Jürimäe J, Purge P \& Jürimäe T. Adiponectin and stress hormone responses to maximal sculling after volume-extended training season in elite rowers. Metabolism: Clinical and Experimental 2006 55 13-19.

37 Jürimäe J, Purge $\mathrm{P} \&$ Jürimäe T. Adiponectin is altered after maximal exercise in highly trained male rowers. European Journal of Applied Physiology and Occupational Physiology 200593 502-505.

38 Ring-Dimitriou S, Paulweber B, von Duvillard SP, Stadlmann M, LeMura LM, Lang J \& Müller E. The effect of physical activity and physical fitness on plasma adiponectin in adults with predisposition to metabolic syndrome. European Journal of Applied Physiology $200698472-481$.

39 Fasshauer M, Kralisch S, Klier M, Lossner U, Bluher M, Klein J \& Paschke R. Adiponectin gene expression and secretion is inhibited by interleukin-6 in 3T3-L1 adipocytes. Biochemical and Biophysical Research Communications 2003301 1045-1050.

40 Febbraio MA \& Pedersen BK. Muscle-derived interleukin-6: mechanisms for activation and possible biological roles. FASEB Journal 200216 1335-1347.

41 Petersen AM \& Pedersen BK. The anti-inflammatory effect of exercise. Journal of Applied Physiology 200598 1154-1162.

42 Menacherry S, Hubert W \& Justice JB, Jr. In vivo calibration of microdialysis probes for exogenous compounds. Analytical Chemistry $199264577-583$.

43 Kehr J. A survey on quantitative microdialysis: theoretical models and practical implications. Journal of Neuroscience Methods 1993 48 251-261.
44 Emoto M, Nishizawa Y, Maekawa K, Hiura Y, Kanda H, Kawagishi T, Shoji T, Okuno Y \& Morii H. Homeostasis model assessment as a clinical index of insulin resistance in type 2 diabetic patients treated with sulfonylureas. Diabetes Care 199922 818-822.

45 Gavrila A, Peng CK, Chan JL, Mietus JE, Goldberger AL \& Mantzoros CS. Diurnal and ultradian dynamics of serum adiponectin in healthy men: comparison with leptin, circulating soluble leptin receptor, and cortisol patterns. Journal of Clinical Endocrinology and Metabolism $2003 \mathbf{8 8} 2838-2843$.

$46 \mathrm{Wu}$ X, Motoshima H, Mahadev K, Stalker TJ, Scalia R \& Goldstein BJ. Involvement of AMP-activated protein kinase in glucose uptake stimulated by the globular domain of adiponectin in primary rat adipocytes. Diabetes 200352 1355-1363.

47 Sell H, Dietze-Schroeder D, Eckardt K \& Eckel J. Cytokine secretion by human adipocytes is differentially regulated by adiponectin, AICAR, and troglitazone. Biochemical and Biophysical Research Communications 2006343 700-706.

48 Bülow J. Adipose tissue blood flow during exercise. Danish Medical Bulletin 198330 85-100.

49 Eisenberg EJ \& Eickhoff WM. A method for estimation of extracellular concentration of compounds by microdialysis using urea as an endogenous recovery marker in vitro validation. Journal of Pharmacological and Toxicological Methods 199330 27-31.

50 Stallknecht B, Kiens B, Helge JW, Richter EA \& Galbo H. Interstitial glycerol concentrations in human skeletal muscle and adipose tissue during graded exercise. Acta Physiologica Scandinavica 2004 180 367-377.

51 Lee MJ \& Fried SK. Multilevel regulation of leptin storage, turnover, and secretion by feeding and insulin in rat adipose tissue. Journal of Lipid Research 200647 1984-1993.

52 Pereira RI \& Draznin B. Inhibition of the phosphatidylinositol 3'-kinase signaling pathway leads to decreased insulin-stimulated adiponectin secretion from 3T3-L1 adipocytes. Metabolism: Clinical and Experimental $2005 \mathbf{5 4} 1636-1643$.

53 Rasouli N, Yao-Borengasser A, Miles LM, Elbein SC \& Kern PA. Increased plasma adiponectin in response to pioglitazone does not result from increased gene expression. American Journal of Physiology. Endocrinology and Metabolism 2006290 E42-E46.

54 Lihn AS, Bruun JM, He G, Pedersen SB, Jensen PF \& Richelsen B. Lower expression of adiponectin mRNA in visceral adipose tissue in lean and obese subjects. Molecular and Cellular Endocrinology 2004219 9-15.

55 Motoshima H, Wu X, Sinha MK, Hardy VE, Rosato EL, Barbot DJ, Rosato FE \& Goldstein BJ. Differential regulation of adiponectin secretion from cultured human omental and subcutaneous adipocytes: effects of insulin and rosiglitazone. Journal of Clinical Endocrinology and Metabolism 200287 5662-5667.

56 Keller C, Keller P, Marshal S \& Pedersen BK. IL-6 gene expression in human adipose tissue in response to exercise - effect of carbohydrate ingestion. Journal of Physiology $2003550927-931$.

57 Sopasakis VR, Sandqvist M, Gustafson B, Hammarstedt A, Schmelz M, Yang X, Jansson PA \& Smith U. High local concentrations and effects on differentiation implicate interleukin- 6 as a paracrine regulator. Obesity Research 200412 454-460.

58 Bernstein EL, Koutkia P, Ljungquist K, Breu J, Canavan B \& Grinspoon S. Acute regulation of adiponectin by free fatty acids. Metabolism: Clinical and Experimental 200453 790-793.

59 Staiger H, Tschritter O, Kausch C, Lammers R, Stumvoll M \& Haring HU. Human serum adiponectin levels are not under shortterm negative control by free fatty acids in vivo. Hormone and Metabolic Research 200234 601-603.

Received 23 June 2007

Accepted 31 August 2007 